\title{
Genetic testing and cancer risk management recommendations by physicians for at-risk relatives
}

\author{
Sharon E. Plon, MD, PhD ${ }^{1,2,3}$, H. Paul Cooper, MA $A^{3,4,5}$, Bethany Parks, MS ${ }^{1}$, Shweta U. Dhar, $M D^{2}$, \\ P. Adam Kelly, PhD ${ }^{4}$, Armin D. Weinberg, PhD ${ }^{3,4,5}$, Stephanie Staggs, $M H A^{5}$, Tao Wang, MS ${ }^{3}$, \\ and Susan Hilsenbeck, $P h D^{3,4}$
}

\begin{abstract}
Purpose: Sequence-based cancer susceptibility testing results are described as negative, deleterious mutation or variant of uncertain significance. We studied the impact of different types of test results on clinical decision making. Methods: Practicing physicians from five specialties in Texas completed an online case-based survey $(n=225)$. Respondents were asked to make genetic testing and management recommendations for healthy at-risk relatives of patients with cancer. Results: When the patient carried a deleterious BRCA1 mutation or variant of uncertain significance, $98 \%$ and $82 \%$ of physicians, respectively, recommended testing of at-risk relatives $(P<0.0001)$. In both situations, comprehensive $B R C A 1 / 2$ analysis was selected most with a corresponding 9-fold increase in unnecessary genetic testing costs. There was no difference in physicians with $(n=81)$ or without $(n=$ $144)$ prior $B R C A 1 / 2$ testing experience $(P=0.3869)$. Cancer risk management recommendations were most intense for the relative with a deleterious mutation compared with variant of uncertain significance, negative, or no testing with $63 \%, 13 \%, 5 \%$, and $2 \%$, respectively, recommending oophorectomy $(P<0.0001)$. Conclusions: Independent of experience, or specialty, physicians chose more comprehensive testing for healthy relatives than current guidelines recommend. In contrast, management decisions demonstrated the uncertainty associated with a variant of uncertain significance. Utilization of genetic professionals and education of physicians on family-centered genetic testing may improve efficacy and substantially reduce costs. Genet Med 2011:13(2):148-154.
\end{abstract}

Key Words: genetic testing, missense mutations, cancer susceptibility, risk management, cost effectiveness

G enetic testing and risk assessment traditionally have been performed by geneticists or other health professionals with genetic expertise. Increasing familiarity with the use of certain genetic tests and the recent growth of direct-to-consumer and physician-centered marketing campaigns by genetic testing laboratories have created increased public awareness and encouraged varied physician specialties to order testing of patients and their at-risk relatives. ${ }^{1,2}$

To identify the specific mutation responsible for hereditary breast and ovarian cancer syndrome (HBOCS) in a given family, sequence-based testing of the entire $B R C A 1$ and $B R C A 2$ coding regions is initiated by testing a family member with cancer. The results can be (a) normal sequence, with no muta-

From the Departments of ${ }^{1}$ Pediatrics and ${ }^{2}$ Molecular and Human Genetics, ${ }^{3}$ Dan L. Duncan Cancer Center, ${ }^{4}$ Department of Medicine, Baylor College of Medicine, Houston; and ${ }^{5}$ Physician Oncology Education Program, Texas Medical Association, Austin, Texas.

Sharon E. Plon, MD, PhD, FACMG, Feigin Center, Room 1200.18, 1102 Bates Street, Houston, TX 77030. E-mail: splon@bcm.edu.

Disclosure: The authors declare no conflict of interest

Published online ahead of print January 10, 2011.

DOI: $10.1097 /$ GIM.0b013e318207f564 tion detected; (b) deleterious mutation; or (c) variant of uncertain significance (VUS). A VUS result is a base change for which there is not sufficient data to determine whether it confers cancer risk or is a benign variant. VUS results occur in approximately $5-15 \%$ of $B R C A 1 / 2$ sequencing tests, with the likelihood dependent on the patient's racial or ethnic background. ${ }^{3}$

Established guidelines for HBOCS, such as those from the National Cancer Care Network (NCCN), recommend that when a deleterious mutation is found in a patient with cancer, at-risk relatives are offered a simplified genetic test for that specific mutation (single-site testing) (http://www.nccn.org; version 1.2010). ${ }^{4}$ Given the uncertainty of the VUS result, genetic testing of at-risk relatives is not recommended. Intensive studies have been done on physician understanding and utilization of deleterious results. ${ }^{5-7}$ However, there is little research on management of patients and family members when a VUS result is identified. On the basis of our own clinical experience, we hypothesized that nongeneticist physicians would characterize VUS results similarly to deleterious mutations with regard to genetic testing, cancer risk estimates and cancer surveillance, and prophylactic surgery recommendations. In this case-based survey study, we specifically compared genetic testing and cancer risk management recommendations for healthy at-risk women when genetic testing identified a deleterious mutation or VUS in their relative with cancer.

\section{MATERIALS AND METHODS}

\section{Design overview}

We designed a case-based survey to assess how physicians of different specialties would use genetic test results for an individual with cancer to make genetic testing and cancer risk management recommendations for their patient who was a healthy at-risk relative. The second part of the survey assessed their prior genetic education and experience with genetic testing for cancer susceptibility. The study was submitted to the Baylor College of Medicine Institutional Review Board and deemed exempt.

\section{Setting and participants}

We collaborated with the Texas Medical Association (TMA) to obtain a sample from their master database of all physicians licensed to practice in the State of Texas, which is derived from multiple membership list sources, including the TMA itself and the Texas Medical Board. The sample included direct patient care providers from five medical specialty groups: family medicine, internal medicine, obstetrics/gynecology, general surgery, and hematology-oncology. Eligibility for inclusion in the sample was restricted to those physicians for whom both postal and email addresses were available (62\% of sampled specialties). Two hundred physicians were randomly selected from each specialty group, for an initial total sample of 1000 . 


\section{Interventions}

Sampled physicians were mailed a survey invitation letter from the TMA Physician Oncology Education Program that explained the purpose of the study, contained a token gift (flash memory drive), and offered a $\$ 50$ incentive for completion of the survey. Up to four follow-up reminder invitations were sent to nonresponders, three by email and one by postal mail. Survey participation invitations were initiated in two batches during the fourth quarter of 2008 and the first quarter of 2009. Survey invitation letters for $28(3 \%)$ of the physicians were returned as undeliverable.

Responders were directed to an online survey form. Each responder logged in using a unique ID code and could exit and reenter the survey multiple times. Submission of the survey required a response to all questions.

\section{Survey instrument}

The survey was presented in two parts: (1) case-based descriptions and questions as described below and (2) questions about a responder's training in genetics, clinical experience with genetic testing, and referral pattern for patients for genetic evaluation in their own practice. We also inquired about barriers to greater use of genetic evaluation, recommendations for improving genetic test reports, and preferred methods for further education on the topic.

Table 1 describes the cases. Each case posed questions regarding the management of a hypothetical healthy woman (without cancer) of age 41-43 years and having a first-degree relative (mother or sister) with breast or ovarian cancer. We provided a text description of family history, and pedigrees were available by hyperlink. Test reports in the survey were modeled after actual BRACAnalysis ${ }^{(\mathcal{B}}$ reports and opened as separate attachments through hyperlinks. In all cases, except Case 1 (no testing), responders were provided the results of comprehensive genetic testing for BRCA1 and BRCA2 of the patient with cancer. Responders were then asked to assess the risk of cancer and recommendations for genetic testing for their patient (the "healthy relative"). Second, testing was performed in all healthy relatives, except Case 1, either as "self-ordered" if the responder chose to recommend testing or as "ordered by another provider." The responders were provided genetic test reports for their patient and asked to reevaluate their cancer risk and make recommendations for cancer risk management and surveillance options. At the end of each case, responders were asked what information they had used or found helpful in making their recommendations for that case.

\section{Statistical analysis}

Descriptive statistics were calculated to compare responders with nonresponders and to compare the demographic characteristics of responders by specialty group using $\chi^{2}$ tests and KruskalWallis rank sum test. McNemar's test was used to compare the differences in physicians' testing recommendations, posttest cancer risk assessment, and surveillance recommendations for the deleterious mutation and VUS cases. Chi-square tests and Fisher exact tests were used to compare the differences between the specialty groups on options for the VUS case. For each analysis, $P$ values of $<5 \%$ were considered significant.

We developed an HBOCS cancer risk management intensity score to assess management of cancer risk across several modalities (Table 2). The score was calculated based on surveillance methods (increasing points for shorter intervals) and prophylactic surgery options, with a maximum possible score of 21. Distributions of scores for each case are shown graphically by histogram and kernel density curves and were compared by pairwise Wilcoxon signed rank test with $P$ values adjusted by Bonferroni method for multiple comparisons.

Table 1 Hereditary breast and ovarian cancer cases described in the survey

\begin{tabular}{|c|c|c|c|}
\hline Case & $\begin{array}{l}\text { Case description: the healthy relative is between } \\
41 \text { and } 43 \mathrm{yr} \text { and is a first-degree relative of a } \\
\text { patient with cancer (breast cancer unless } \\
\text { otherwise specified) }\end{array}$ & Test result of patient with cancer & Healthy relative's test result \\
\hline 1 & $\begin{array}{l}\text { Patient with cancer diagnosed at the age of } 43 \\
\text { yr, no genetic testing performed; sister seeks } \\
\text { counseling }\end{array}$ & N/A & N/A \\
\hline $2 \mathrm{a}$ & $\begin{array}{l}\text { Patient with ovarian cancer diagnosed at the age } \\
\text { of } 59 \mathrm{yr} \text {, family history of breast cancer, } \\
\text { proceeds with genetic testing; Daughter A } \\
\text { seeks counseling }\end{array}$ & $\begin{array}{l}\text { Positive for deleterious mutation in } \\
\quad B R C A 1\end{array}$ & $\begin{array}{l}\text { Positive for } B R C A 1 \text { familial } \\
\text { mutation }\end{array}$ \\
\hline $2 b$ & Daughter B seeks counseling & & $\begin{array}{l}\text { Negative for } B R C A 1 \text { familial } \\
\text { mutation }\end{array}$ \\
\hline 3 & $\begin{array}{l}\text { Patient with cancer diagnosed at the age of } 42 \\
\text { yr, proceeds with genetic testing; sister seeks } \\
\text { counseling }\end{array}$ & $\begin{array}{l}\text { VUS identified in } B R C A 1 \text { (sparse } \\
\text { information provided on VUS) }\end{array}$ & $\begin{array}{l}\text { Positive for VUS identified in } \\
\text { patient with Cancer }\end{array}$ \\
\hline $4 a$ & $\begin{array}{l}\text { Patient with cancer diagnosed at the age of } 45 \\
\text { yr, proceeds with genetic testing; daughter } \\
\text { seeks counseling }\end{array}$ & $\begin{array}{l}\text { Positive for both deleterious mutation } \\
\text { and VUS in } B R C A 1 \text { (significant } \\
\text { data on VUS to suggest likely not } \\
\text { cancer associated) }\end{array}$ & $\begin{array}{l}\text { Positive for } B R C A 1 \text { familial } \\
\text { mutation and VUS }\end{array}$ \\
\hline $4 \mathrm{~b}$ & $\begin{array}{l}\text { Patient with cancer (sister to patient with } \\
\text { cancer, Case } 4 a \text { ) diagnosed at the age of } 68 \\
\text { yr, proceeds with genetic testing; daughter } \\
\text { seeks counseling }\end{array}$ & $\begin{array}{l}\text { Negative for } B R C A 1 \text { familial } \\
\text { mutation, but positive for VUS }\end{array}$ & $\begin{array}{l}\text { Negative for } B R C A 1 \text { familial } \\
\text { mutation and VUS }\end{array}$ \\
\hline
\end{tabular}

VUS, variant of uncertain significance; N/A, not applicable. 
Table 2 Hereditary breast and ovarian cancer syndrome cancer risk management intensity score

\begin{tabular}{lcccc}
\hline & \multicolumn{4}{c}{ Interval of screening } \\
\cline { 2 - 5 } Screening test & 6 mo & 12 mo & 24 mo & Not appropriate \\
\hline Clinical breast examination & 3 & 2 & 1 & 0 \\
Mammogram & 3 & 2 & 1 & 0 \\
Breast MRI & 3 & 2 & 1 & 0 \\
Transvaginal sonogram & 3 & 2 & 1 & 0 \\
Blood CA-125 level & 3 & 2 & 1 & 0 \\
Prophylactic surgery & Yes & No & & \\
Bilateral mastectomy & 3 & 0 & & \\
Bilateral oophorectomy & 3 & 0 &
\end{tabular}

The points attributed for each question regarding cancer surveillance and prophylactic surgery are provided. Score $=$ sum of all measures indicated by the respondent.

\section{RESULTS}

We present results from a case-based survey of practicing physicians in Texas from five different specialties. We assessed responders' recommendations for genetic testing, cancer surveillance, and prophylactic surgery for at-risk women ("healthy relative") with a first-degree family member, mother or sister, with breast or ovarian cancer ("patient with cancer"). Cases included patients with cancer with no genetic testing, BRCAI deleterious mutation, $B R C A 1$ VUS, or both. We also queried each responder about his or her exposure to genetics in preor postgraduate medical training and his or her experience with genetic testing for cancer susceptibility in his or her own practice.

\section{Survey response}

A total of 225 completed surveys were submitted from the 972 physicians from whom our survey invitation letter was not returned as undeliverable (response rate $=23 \%$ ). Detailed demographic information was available for both responders and nonresponders (Table 3). Comparison of these nine variables revealed that the only significant difference was mean years in practice (14.2 years for responders vs. 16.7 years for nonresponders; Kruskal-Wallis rank sum $P=0.004$ ). Among the responders, comparisons across the five specialties revealed statistical differences on many demographic characteristics; however, the majority of responders in all specialty groups were in some form of office-based practice, and $84 \%$ spent their time on direct patient care.

\section{Genetic testing recommendations}

For Cases $2 \mathrm{a}-4 \mathrm{~b}$, after being provided the results of comprehensive $B R C A 1$ and $B R C A 2$ testing for the patient with cancer, responders were asked to estimate breast and ovarian cancer risk of the first-degree healthy relative (sister or daughter) and whether genetic testing was indicated. The physicians were offered six genetic testing options, which resemble those available in the United States: comprehensive BRCA1 and $B R C A 2$ testing, BRCA1 testing only, BRCA2 testing only, Ashkenazi Panel for three mutations, Single-Site Testing, and Testing Not Appropriate. Definitions of each test type were provided by hyperlink.
Overall, the majority of responders recommended genetic testing for at-risk healthy relatives, regardless of the type of alteration (deleterious or VUS) identified in the patient with cancer (Fig. 1). For Case 2 with a deleterious BRCA1 mutation identified in the mother with ovarian cancer, testing of the daughters was recommended by $98 \%$ of the physician responders. However, to our surprise, only $20.4 \%$ of responders chose the NCCN recommended single-site option (Fig. 1A). Hematology-oncology physicians chose single-site testing more frequently than other specialties $\left(38.7 \% ; \chi^{2}\right.$ test, $P=0.02$ ). Results for Case $4 \mathrm{a}$, which also had a patient with cancer with a deleterious mutation, were similar (data not shown).

In Case 3, a BRCA1 VUS mutation was identified in the patient with cancer. There was little information provided in the report to determine pathogenicity of the VUS. Responders did choose "Testing Not Appropriate" (the NCCN recommendation) more often than in Case 2 (18\% vs. $2 \%$; McNemar's test, $P<0.0001)$; however, $82 \%$ of all responders recommended some level of genetic testing for the at-risk relative (Fig. 1B) with no significant differences among specialties $\left(\chi^{2}\right.$ test, $P=$ 0.10). In Case $4 b$, the patient with cancer had a VUS where the data provided on the report strongly suggested that it was not pathogenic, but the testing recommendations for the at-risk relative were similar to Case 3 (data not shown).

Across specialties, responders most frequently chose "Comprehensive $B R C A 1$ and $B R C A 2$ testing" for the healthy relative when the patient with cancer carried either a deleterious mutation or a VUS, $51 \%$ or $54 \%$, respectively. We scored each responder for whether they selected the genetic test recommended by the NCCN guidelines for healthy at-risk relatives in four situations ("single-site testing" for Cases 2 and $4 \mathrm{a}$ and "testing not appropriate" for Cases 3 and $4 \mathrm{~b}$ ). Of all responders, $87 \%$ had zero genetic testing questions or one genetic testing question correct, and only $2 \%(n=5)$ answered all four questions correctly. We next determined whether physician experience with $B R C A 1 / 2$ testing in his or her own clinical practice impacted this score as during the survey the physicians were provided the $B R C A 1 / 2$ genetic test report without any other educational literature about genetic testing. When segregated by experience with $B R C A 1 / 2$ testing (Fig. 1C), physicians with experience $(n=81)$ did not score any better than those without previous experience $(n=144$; Fisher exact test, $P=$ 0.39 ). The cost for comprehensive $B R C A 1 / 2$ analysis in the United States is approximately $\$ 3340$, whereas the cost for single-site analysis is $\$ 475$. We calculated the total cost of the four test recommendations for each respondent (Fig. 1D). The median cost was $\$ 10,020$ compared with $\$ 950$ for the NCCN recommended strategy.

\section{Posttest cancer risk assessment}

In each case, the responders were then given the healthy relatives' genetic test report and asked whether the posttest breast cancer and ovarian cancer risk was higher, same, or lower than pretest. When the healthy relative was positive for the deleterious BRCA1 mutation, 70\% of all responders assessed the breast cancer risk as "Higher." In contrast, for Case 3 where the relative carries the VUS, only $27 \%$ assessed a "Higher" posttest cancer risk even though $82 \%$ of responders had recommended genetic testing. The difference in posttest cancer risk assessment between VUS and deleterious mutation is highly significant (McNemar's test, $P<0.0001$ ). There were no significant differences among specialties for posttest risk assessment ( $\chi^{2}$ test, $P=0.75$ ). Posttest risk estimates for breast and ovarian cancer were similar in all cases. 
Table 3 Demographic description of physician responders and nonresponders

\begin{tabular}{|c|c|c|c|c|c|c|c|c|}
\hline \multirow[b]{2}{*}{ Variables } & \multirow[b]{2}{*}{$\begin{array}{l}\text { Nonresponders, all } \\
\quad(N=747)\end{array}$} & \multicolumn{6}{|c|}{ Responders } & \multirow[b]{2}{*}{$P^{a}$} \\
\hline & & $\begin{array}{c}\text { All } \\
(N=225)\end{array}$ & $\begin{array}{c}\mathrm{FM} \\
(N=50)\end{array}$ & $\begin{array}{c}\mathrm{IM} \\
(N=48)\end{array}$ & $\begin{array}{c}\mathrm{OG} \\
(N=51)\end{array}$ & $\begin{array}{c}\text { GS } \\
(N=45)\end{array}$ & $\begin{array}{c}\mathrm{HO} \\
(N=31)\end{array}$ & \\
\hline \multicolumn{9}{|l|}{ Gender } \\
\hline Female & $30 \%$ & $30 \%$ & $32 \%$ & $35 \%$ & $41 \%$ & $16 \%$ & $19 \%$ & \multirow[t]{2}{*}{0.041} \\
\hline Male & $70 \%$ & $70 \%$ & $68 \%$ & $65 \%$ & $59 \%$ & $84 \%$ & $81 \%$ & \\
\hline \multicolumn{9}{|l|}{ Ethnicity } \\
\hline White & $55 \%$ & $54 \%$ & $50 \%$ & $42 \%$ & $66 \%$ & $59 \%$ & $55 \%$ & \\
\hline Black & $5 \%$ & $4 \%$ & $4 \%$ & $6 \%$ & $4 \%$ & $5 \%$ & $0 \%$ & \\
\hline Hispanic & $12 \%$ & $10 \%$ & $12 \%$ & $10 \%$ & $4 \%$ & $16 \%$ & $7 \%$ & \\
\hline Asian, Pacific Islander & $14 \%$ & $17 \%$ & $20 \%$ & $25 \%$ & $6 \%$ & $9 \%$ & $29 \%$ & \\
\hline Unknown & $14 \%$ & $15 \%$ & $14 \%$ & $17 \%$ & $20 \%$ & $11 \%$ & $10 \%$ & \\
\hline \multicolumn{9}{|l|}{ Years in practice } \\
\hline Mean years & 16.7 & 14.2 & 15.5 & 9.2 & 16.7 & 15.4 & 14.3 & $0.0039,0.004^{b}$ \\
\hline \multicolumn{9}{|l|}{ Practice environment } \\
\hline Solo practice & $37 \%$ & $31 \%$ & $39 \%$ & $22 \%$ & $32 \%$ & $44 \%$ & $8 \%$ & \multirow[t]{6}{*}{0.0040} \\
\hline Two physician practice & $8 \%$ & $8 \%$ & $10 \%$ & $4 \%$ & $12 \%$ & $9 \%$ & $0 \%$ & \\
\hline Multispecialty group practice & $10 \%$ & $17 \%$ & $26 \%$ & $19 \%$ & $12 \%$ & $12 \%$ & $16 \%$ & \\
\hline Single-specialty group practice & $32 \%$ & $30 \%$ & $21 \%$ & $22 \%$ & $29 \%$ & $24 \%$ & $64 \%$ & \\
\hline Academic setting & $11 \%$ & $11 \%$ & $0 \%$ & $30 \%$ & $10 \%$ & $9 \%$ & $12 \%$ & \\
\hline Other & $2 \%$ & $3 \%$ & $4 \%$ & $3 \%$ & $5 \%$ & $2 \%$ & $0 \%$ & \\
\hline \multicolumn{9}{|l|}{ Practice location } \\
\hline Office based & $86 \%$ & $83 \%$ & $100 \%$ & $44 \%$ & $97 \%$ & $78 \%$ & $88 \%$ & \multirow[t]{4}{*}{$<0.0001$} \\
\hline Hospital based & $5 \%$ & $9 \%$ & $0 \%$ & $30 \%$ & $3 \%$ & $19 \%$ & $0 \%$ & \\
\hline Medical school or university & $6 \%$ & $6 \%$ & $0 \%$ & $17 \%$ & $0 \%$ & $4 \%$ & $12 \%$ & \\
\hline Other & $3 \%$ & $1 \%$ & $0 \%$ & $9 \%$ & $0 \%$ & $0 \%$ & $0 \%$ & \\
\hline \multicolumn{9}{|l|}{ Type of practice } \\
\hline Direct patient care & $87 \%$ & $84 \%$ & $96 \%$ & $85 \%$ & $84 \%$ & $80 \%$ & $65 \%$ & \multirow[t]{3}{*}{$<0.0001$} \\
\hline Direct patient care and research & $4 \%$ & $5 \%$ & $0 \%$ & $4 \%$ & $0 \%$ & $2 \%$ & $29 \%$ & \\
\hline Direct patient care and teaching & $10 \%$ & $11 \%$ & $4 \%$ & $10 \%$ & $16 \%$ & $18 \%$ & $7 \%$ & \\
\hline \multicolumn{9}{|l|}{ American Medical Association } \\
\hline Membership & $26 \%$ & $24 \%$ & $22 \%$ & $10 \%$ & $26 \%$ & $31 \%$ & $32 \%$ & \\
\hline \multicolumn{9}{|l|}{ Texas Medical Association } \\
\hline Membership & $85 \%$ & $84 \%$ & $76 \%$ & $79 \%$ & $80 \%$ & $93 \%$ & $100 \%$ & 0.012 \\
\hline \multicolumn{9}{|l|}{ County Medical Society } \\
\hline Membership & $85 \%$ & $84 \%$ & $76 \%$ & $79 \%$ & $78 \%$ & $93 \%$ & $100 \%$ & 0.010 \\
\hline
\end{tabular}

Only significant $P$ values are shown.

${ }^{a} P$ values were calculated to compare the difference of the demographic characteristics of responders between specialty group by Kruskal-Wallis rank sum test for "Years in Practice" and $\chi^{2}$ tests for the others (see "Materials and Methods").

${ }^{b} P$ value comparing responders to nonresponders for years in practice (Kruskal-Wallis rank sum test).

FM, family medicine; IM, internal medicine; GS, general surgery; OG, obstetrics/gynecology; HO, hematology-oncology. 
A Cancer patient with BRCA1 mutation

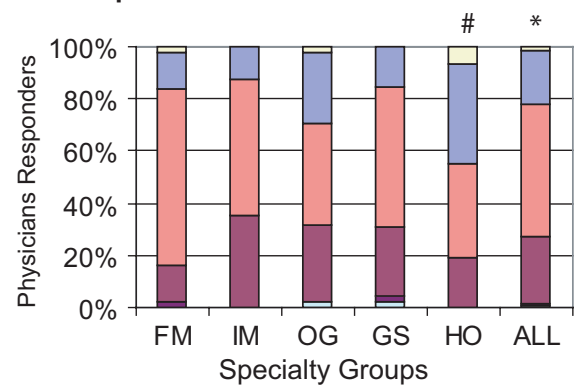

C Testing recommendation scores

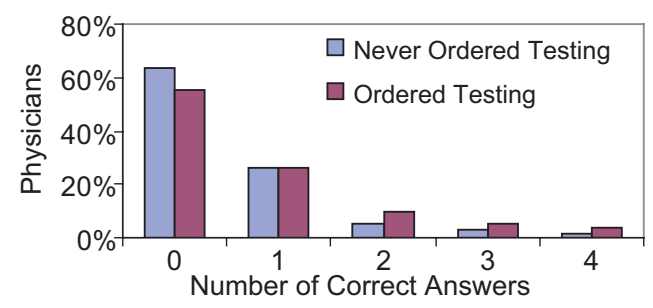

B Cancer patient with BRCA1 VUS

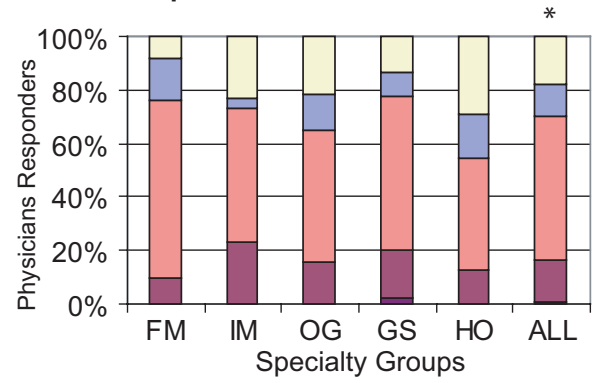

$\square$ Testing not appropriate

$\square$ Single-Site

$\square$ Comprehensive BRCA1/2

$\square$ BRCA1 only

$\square$ Ashkenazi Panel

$\square$ BRCA2 only

D Total costs of genetic testing recommendations

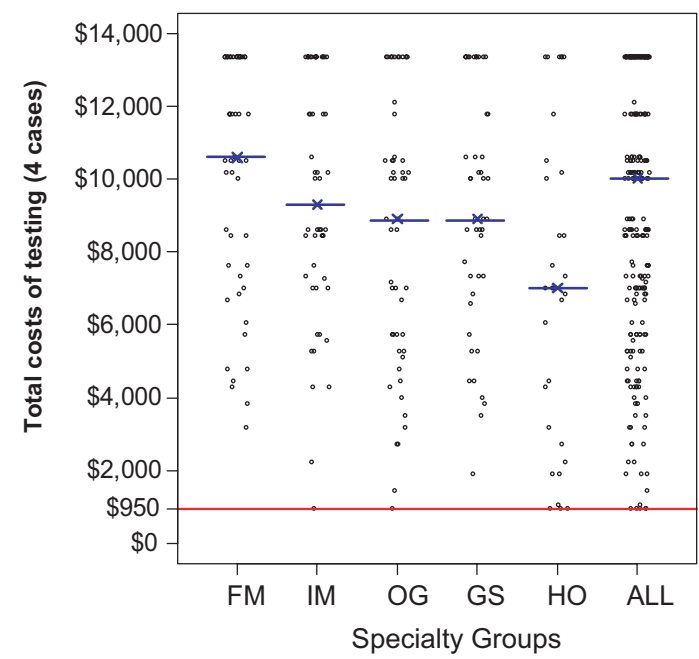

Fig. 1. Physician recommendation for genetic testing of healthy at-risk women based on the test result of their relative with cancer. A, Recommendations for the daughters of a woman with ovarian cancer who was found to carry a deleterious BRCA1 mutation (Case 2). B, Recommendations for the sister of a woman with breast cancer who was found to carry a variant of uncertain significance (VUS) in BRCA1 (Case 3). Legend depicts the six test types provided in the survey. *Testing not appropriate ( $2 \%$ vs. $18 \%$; McNemar's test, $P<0.0001$ ); \#single-site testing selection by $\mathrm{HO}$ at $38.7 \%$ vs. $20.4 \%$ overall ( $\chi^{2}$ test, $\left.P=0.02\right)$. C, The number of test questions answered in accordance with the NCCN guidelines stratified by physician experience with $B R C A 1 / 2$ genetic testing. D, Total cost of the genetic tests recommended by each respondent. X with horizontal line marks the median costs for each group. Red line demarcates total costs, $\$ 950$, if questions were answered per NCCN guidelines. FM, family medicine; IM, internal medicine; OG, obstetrics/gynecology; GS, general surgery; HO, hematology-oncology; all, total sample.

\section{Cancer management and surveillance recommendations}

After reviewing test reports, responders were asked to make recommendations on the type and interval of cancer surveillance and prophylactic surgery options for these healthy women. We developed an HBOCS cancer risk management intensity score with points allotted for the type and interval of surveillance methods and prophylactic surgery (Table 2). The distribution of scores in Figure 2 demonstrates that responders recommended significantly more intense screening/surgery for the relative with a deleterious $B R C A 1$ mutation compared with the other three scenarios. Although less intense than for a deleterious mutation, physicians did recommend more screening for the relative with a VUS result (Fig. 2D) compared with a similar family without testing (Fig. 2A). The extended tail in the intensity score distribution for the individuals with either a deleterious or VUS result (Fig. 2, Panels C and D) demonstrates a broad range of physician responses for both of these important clinical scenarios.

We specifically examined two components of the NCCN guidelines, prophylactic oophorectomy and breast magnetic resonance imaging (MRI) (Fig. 3). Similar to intensity score, physicians recommended oopherectomy most frequently in the healthy relative with a deleterious mutation at $63 \%$ vs. $13 \%$ for the VUS result (McNemar's test, $P<0.0001$ ), although VUS was still greater than the $2.2 \%$ for a relative with the same cancer history who had no testing (McNemar's test, $P<$ 0.0001 ). For breast MRI, $76 \%$ of responders recommended MRI (annual surveillance was the screening interval chosen most often) for healthy relatives with a deleterious mutation compared with only $38 \%$ for the VUS result (McNemar's test, $P<$ 0.0001). Comparing different specialties (data not shown), general surgeons (24\%) were more likely to recommend oopherectomy for women with a VUS than other responders (average 


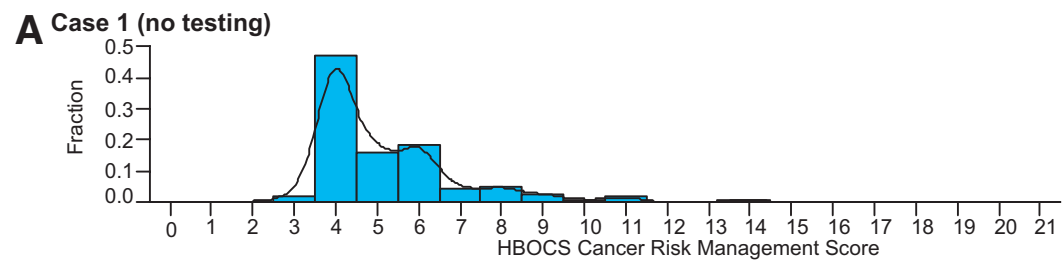

$B$ Case 2b (negative)

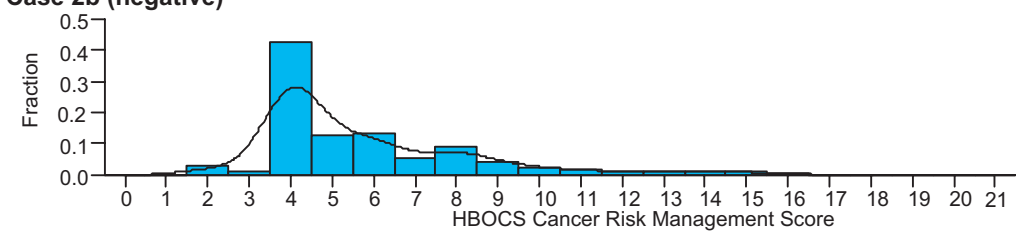

C Case 2a (positive deleterious mutation)*

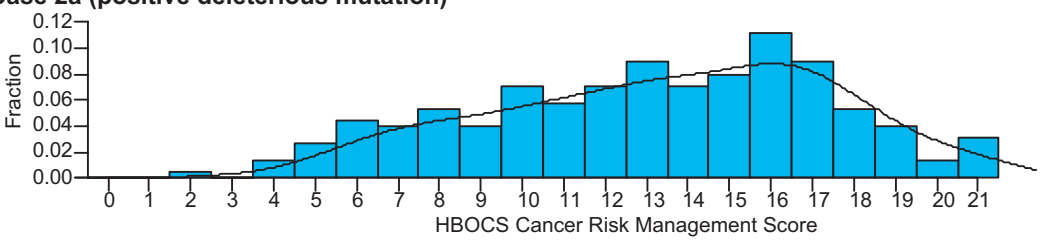

D Case 3 (positive VUS)\#

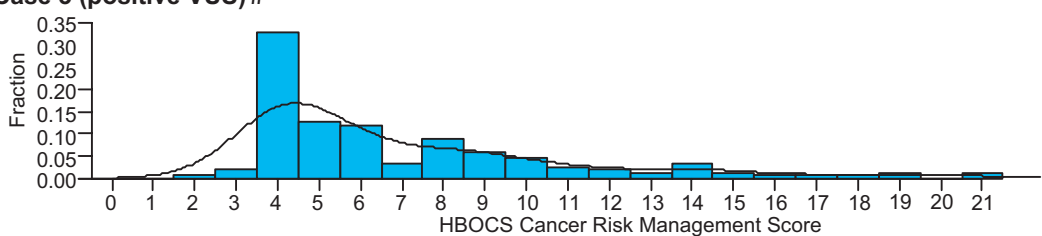

Fig. 2. Hereditary breast and ovarian cancer syndrome (HBOCS) cancer risk management intensity score for healthy at-risk relatives. Histogram of physician responders in four different situations: (A) sister of a relative with breast cancer and no testing performed (Case 1), (B) daughter who is negative for BRCA1 deleterious mutation found in mother (Case $2 \mathrm{~b}$ ), (C) daughter positive for $B R C A 1$ deleterious mutation found in mother (Case 2a), and (D) sister positive for $B R C A 1$ variant of uncertain significance (VUS) found in woman with breast cancer (Case 3). Distributions for the woman with a deleterious mutation (C)* and VUS (D)\# are each different from the other three (Wilcoxon signed rank test, $P<0.0001$ ). Distributions for no testing $(A)$ and negative $(B)$ result are not different from each other (Wilcoxon signed rank test, $P=$ 0.071).

$11 \%)\left(\chi^{2}\right.$ test, $\left.P=0.03\right)$, although there was no difference among specialties for MRI recommendation $\left(\chi^{2}\right.$ test, $\left.P=0.22\right)$.

\section{DISCUSSION}

As the number of nongeneticist physicians ordering sequence-based genetic testing increases, it is important to understand how they make decisions with regard to genetic testing and risk management for the healthy at-risk relatives of patients who have undergone testing and whether those decisions are appropriate. Although we acknowledge that the low response rate from the sampled physicians is a limitation, previous studies based on physician surveys have reported comparable response rates. ${ }^{8,9}$ In our study, detailed demographic and practice information was available on the nonresponders and demonstrated that the only feature that varied between responders and nonresponders was time in practice. Given the relatively new development of genetic testing for cancer risk, one would assume that the slightly shorter time in practice of responders would reflect a higher likelihood of education on genetic testing and, if anything, provide a rosier picture of physician knowledge than is warranted. Although our data are limited to physicians practicing in the state of Texas, the Kaiser Family Foundation analysis of the demographic dis- tribution of physicians in Texas compared with the corresponding national distribution shows remarkable consistency for physician density, gender, race, percent primary care physicians, and the specialty breakdown of primary care physicians (http://www.statehealthfacts.org).

Overall, the survey results demonstrate a seemingly contradictory picture between decisions about testing and subsequent risk management. Physicians overwhelmingly recommended testing for a healthy relative when the patient with cancer has an uncertain VUS result even though this is an inappropriate strategy, and NCCN guidelines do not recommend testing in that situation given the uncertain disease association of the variant. However, if the healthy relative is found to carry the VUS, only a minority of physicians thought that her cancer risk had increased or measures such as MRI or prophylactic surgery were indicated. It should be noted that more physicians recommended more intense management (including 13\% recommending oopherectomy) for a relative with a VUS compared with a woman who has a similar family cancer history without testing, thus further education on the interpretation of variants is warranted. However, the recommendations for a deleterious BRCA1 mutation carrier were significantly more intense than the VUS result. Thus, the majority of physician respondents demonstrate appreciation for the uncertainty associated with a VUS result, and our 


\section{A Oopherectomy recommendations}

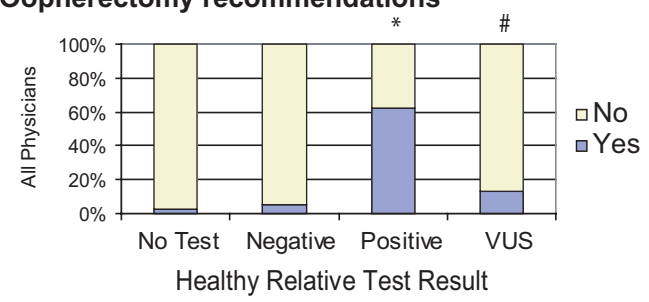

\section{B MRI recommendations}

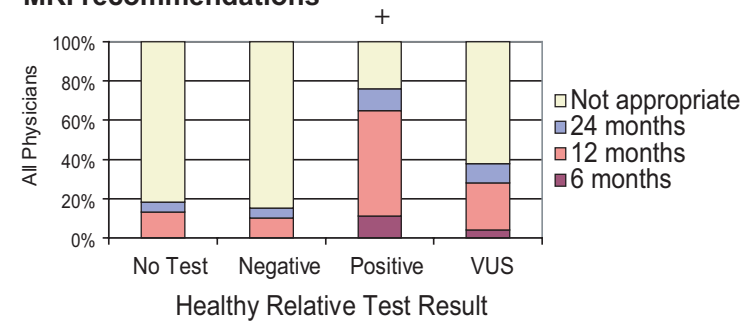

Fig. 3. Physician recommendations for cancer risk management of healthy at-risk relative. Results from four situations are depicted (see legend of Fig. 2). Results from all physician responders were pooled: $(A)$ recommendation for oophorectomy, (B) recommendation for breast MRI and interval of screening. *Oophorectomy recommended $63 \%$ (positive) vs. 13\% (VUS) (McNemar's test, $P<$ $0.0001)$; \#oophorectomy recommended 13\% (VUS) vs. $2 \%$ (no testing) (McNemar's test, $P<0.0001$ ); and + breast MRI 76\% (mutation) vs. 38\% (VUS) (McNemar's test, $P<0.0001)$. MRI, magnetic resonance imaging.

initial hypothesis that physicians would manage cancer risk in healthy women carrying a VUS similarly to a deleterious mutation was disproven.

Genetic test request forms require the ordering physician to designate the type of test being ordered and, if single-site testing is chosen, provide the specific mutation identified in the family member with cancer. An unexpected finding from this survey was the significant preference of physicians for comprehensive $B R C A 1 / 2$ sequencing of the healthy relative whether the patient with cancer had a VUS or deleterious mutation. This preference for comprehensive testing existed even though the survey modeled somewhat ideal conditions, as physicians were provided the genetic test report of the patient with cancer documenting the specific mutation or VUS with an interpretation of the result to facilitate their testing decisions. Physicians who reported clinical experience with $B R C A 1 / 2$ testing did not score any better in the questions about genetic testing. Very few physicians in any specialty answered at least three of the four genetic testing questions correctly. Other investigators also found that clinical experience did not impact knowledge of cancer genetics. ${ }^{8}$ The lack of knowledge on the process of family-based testing leads to substantially increased testing costs. Thus, although the total cost of appropriate testing in the four testing questions ("single-site analysis" for the two deleterious BRCA1 mutations and "testing not appropriate" for the two VUS situations) is $\$ 950$, the median cost of recommendations by physicians was 10 -fold greater.

In many countries, including in Europe and Australia, guidelines for $B R C A 1 / 2$ testing require pretest and posttest genetic counseling by adequately trained professionals. ${ }^{10,11}$ Comparable regulatory agencies in the United States have no such requirements despite recommendations from a number of task forces and advisory committees. ${ }^{2,12}$ A common reason cited for not pursuing more regulation of the genetic testing process is the financial cost. ${ }^{12}$ However, our results demonstrate that future cost-effective analyses should include the potential for inappropriate ordering of complex genetic testing for family members when measuring the total costs of genetic evaluation. DNA sequence-based testing is now used for a wide variety of medical conditions and is likely to substantially increase in scale with genomic sequencing. The testing process is relatively unique among medical practice in that the specific test recommended for the healthy relative is based on the patient's genetic test result (which may have been ordered by a different physician), but the type of genetic test ordered for the healthy relative is different than that performed on the patient, e.g., single site versus comprehensive sequencing. Utilization of genetics professionals and education of physicians on both the concept of family-based testing and the approach to uncertain variants is clearly needed to improve efficacy and reduce costs associated with genetic testing.

\section{ACKNOWLEDGMENTS}

This work was supported by NIH R01HG004064 (to S.E.P.). The authors acknowledge Claire Noll with work on survey design, Stephanie Gutierrez for data management, and the Physician Oncology Education Program Steering Committee for help in completing this study.

\section{REFERENCES}

1. Keating NL, Stoeckert KA, Regan MM, Digianni L, Garber JE. Physicians' experiences with BRCA1/2 testing in community settings. J Clin Oncol 2008;26:5789-5796.

2. Javitt GH. Policy implications of genetic testing: not just for geneticists anymore. Adv Chronic Kidney Dis 2006;13:178-182.

3. Kurian AW. BRCA1 and BRCA2 mutations across race and ethnicity: distribution and clinical implications. Curr Opin Obstet Gynecol 2010;22: 72-78.

4. National Comprehensive Cancer Network. Genetic/familial high-risk assessment: breast and ovarian v. 1.2010. Available at: http://www ncen org/ professionals/physician gls/PDF/genetics screening pdf [serial online] 10 A.D. Accessed July 6, 2010.

5. Wideroff L, Vadaparampil ST, Greene MH, Taplin S, Olson L, Freedman AN. Hereditary breast/ovarian and colorectal cancer genetics knowledge in a national sample of US physicians. J Med Genet 2005;42:749-755.

6. Baars MJ, Henneman L, Ten Kate LP. Deficiency of knowledge of genetics and genetic tests among general practitioners, gynecologists, and pediatricians: a global problem. Genet Med 2005;7:605-610.

7. Domanska K, Carlsson C, Bendahl PO, Nilbert M. Knowledge about hereditary nonpolyposis colorectal cancer; mutation carriers and physicians at equal levels. BMC Med Genet 2009;10:30.

8. Doksum T, Bernhardt BA, Holtzman NA. Does knowledge about the genetics of breast cancer differ between nongeneticist physicians who do or do not discuss or order BRCA testing? Genet Med 2003;5:99-105.

9. Kahn JA, Cooper HP, Vadaparampil ST, et al. Human papillomavirus vaccine recommendations and agreement with mandated human papillomavirus vaccination for 11-to-12-year-old girls: a statewide survey of Texas physicians. Cancer Epidemiol Biomarkers Prev 2009;18:2325-2332.

10. National Pathology Accreditation Advisory Council. Classification of human genetic testing. Laboratory accreditation standards and guidelines for nucleic acids detection and analysis. Australia: Austrailian Government of Health and Ageing, 2007. Available at: http://www.health.gov.au/internet/ main/publishing.nsf/Content/npaac-classhgt07-toc. Accessed January 4, 2010.

11. Rantanen E, Hietala M, Kristoffersson U, et al. Regulations and practices of genetic counselling in 38 European countries: the perspective of national representatives. Eur J Hum Genet 2008;16:1208-1216.

12. Javitt GH, Hudson K. Federal neglect: regulation of genetic testing. Issues Sci Technol 2006;22:59-66. 